\title{
Crystal methamphetamine and initiation of injection drug use among street-involved youth in a Canadian setting
}

\author{
Dan Werb MSc, Thomas Kerr PhD, Jane Buxton MBBS MHSc, Jeannie Shoveller PhD, Chris Richardson PhD, \\ Julio Montaner MD, Evan Wood MD PhD
}

\begin{abstract}
- Abstract
Background: Although injection drug use is known to result in a range of health-related harms, including transmission of HIV and fatal overdose, little is known about the possible role of synthetic drugs in injection initiation. We sought to determine the effect of crystal methamphetamine use on risk of injection initiation among street-involved youth in a Canadian setting.
\end{abstract}

Methods: We used Cox regression analyses to identify predictors of injection initiation among injection-naive street-involved youth enrolled in the At-Risk Youth Study, a prospective cohort study of street-involved youth in Vancouver, British Columbia. Data on circumstances of first injection were also obtained.

Results: Between October 2005 and November 2010, a total of 395 drug injection-naive, street- involved youth provided 1434 observations, with $64(16.2 \%)$ participants initiating injection drug use during the follow-up period, for a cumulative incidence of 21.7 (95\% confidence interval [Cl] 1.7-41.7) per 100 person-years. In multivariable analysis, recent noninjection use of crystal methamphetamine was positively associated with subsequent injection initiation (adjusted hazard ratio $1.93,95 \% \mathrm{Cl} 1.31-2.85)$. The drug of first injection was most commonly reported as crystal methamphetamine (14/31 [45\%]).

Interpretation: Noninjection use of crystal methamphetamine predicted subsequent injection initiation, and crystal methamphetamine was the most commonly used drug at the time of first injection. Evidence-based strategies to prevent transition to injection drug use among crystal methamphetamine users are urgently needed.

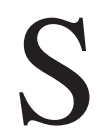
treet-involved youth are at high risk of initiating injection drug use. ${ }^{1}$ This situation is of concern, given that injection drug use has been associated with increased risk of transmission of $\mathrm{HIV}$ and hepatitis $\mathrm{C}$ virus ${ }^{2,3}$ and fatal overdose, ${ }^{4}$ as well as a range of other serious negative health and social outcomes. Newly initiated injection drug users have also been identified as a subpopulation at particularly high risk of injection-related harm..$^{5-8}$ Unfortunately, despite recent calls to prioritize interventions to prevent the initiation of injection drug use, ${ }^{9}$ there are few evidencebased strategies to prevent injection initiation among street-involved youth.

This situation relates, in part, to the fact that little is known about the risk factors for injection initiation within this population. Prospective research from Montréal, Quebec, has alluded to the role that crack and powder cocaine may play in promoting subsequent injection initiation, ${ }^{10}$ as has retrospective research conducted among drug users in Baltimore, Maryland. ${ }^{11}$ Much less is known about the possible role that synthetic drugs, such as methamphetamine, may play in contributing to an increased risk of injection initiation. ${ }^{12}$ Globally, amphetamine-type stimulants have emerged as one of the most commonly used groups of illicit drugs, second only to cannabis. ${ }^{13}$ This increase in amphetamine use is reflected in the epidemiology of drug use in some Canadian settings. For instance, in Vancouver, British Columbia, rates of injection use of crystal methamphetamine have increased significantly among adult injection drug users. ${ }^{14}$ This pattern is of substantial public health concern, given that crystal methamphetamine has been associated with a range of health and social harms, including the potential to drive high-risk drug-use patterns, including injection. ${ }^{15}$ Given these concerns and the well-established health-related harms of injection drug use, we investigated the possible role of crystal methamphetamine use in the incidence of first injection drug use within a cohort of street-involved youth in a Canadian setting.

\section{Methods}

The At-Risk Youth Study, established in 2005, is an open and ongoing prospective cohort study of street-involved youth aged 14 to 26 years based
Competing interests: Julio Montaner has received grants from, served as an ad hoc adviser to or spoken at events sponsored by Abbott, Argos Therapeutics, Bioject Inc., Boehringer Ingelheim, BMS, Gilead Sciences, GlaxoSmithKline, Hoffmann-La Roche, Janssen-Ortho, Merck Frosst, Panacos, Pfizer Ltd., Schering, Serono Inc., TheraTechnologies, Tibotec $(\mathrm{J} \& \mathrm{~J})$ and Trimeris. He has also received grant funding from the BC Ministry of Health, the US National Institute on Drug Abuse, Merck, Janssen and ViiV Healthcare for the STOP (Seek and Treat for Optimal outcomes and Prevention) in HIV \& AIDS in IDU initiative. None declared for Dan Werb, Thomas Kerr, Jane Buxton, Jeannie Shoveller, Chris Richardson or Evan Wood.

This article has been peer reviewed.

Correspondence to: Evan Wood, uhri-ew@cfenet.ubc.ca

CMAJ 2013. DOI:10.1503 /cmaj.130295 
in Vancouver. ${ }^{12}$ All study participants were recruited through street outreach and self-referral. Consistent with previous studies of streetinvolved youth populations, ${ }^{10,16,17}$ potential participants were eligible if they had used illicit drugs other than marijuana in the past 30 days, if they provided written informed consent and if they were "street-involved." Although there was no specific requirement that youth spend a minimum amount of time on the street to qualify for the study, in practice, the street-based recruitment produced a sample of youth who spent extensive time on the street, a large proportion of whom were homeless. Nevertheless, because our study lacked an explicit requirement that participants be living on the street, we use the term "street-involved youth," rather than "street youth," since the latter term is generally applied to youth known to live full-time or part-time on the street. ${ }^{18}$ Once enrolled, participants completed an interviewer-administered questionnaire (available by request to the corresponding author) at baseline, as well as physical and mental health assessments, including blood sampling for diagnostic testing and assessment for physical stigmata of injection drug use (i.e., track lines). Participants subsequently underwent physical examinations and completed interviewer-administered questionnaires semiannually; the questionnaires solicited basic sociodemographic and drug-use data, along with data on other relevant behaviours, including injection of drugs. Participants were given a $\$ 20$ honorarium at each visit. The study has been approved by the University of British Columbia/Providence Health Care Ethics Review Board.

The study presented here includes data collected from street-involved youth who were drug injection-naive, who were enrolled in the At-Risk Youth Study cohort between Oct. 1, 2005, and Nov. 30, 2010, and who completed at least one follow-up interview. The outcome of interest was a first episode of any injection drug use. The primary independent variable of interest was any noninjection use of crystal methamphetamine (i.e., smoking and/or intranasal use) in the previous 6 months. Potential confounders identified in the literature and included in the study were age, ${ }^{10}$ sex (i.e., male v. female or male-to-female transgender), ethnicity (white v. other), ${ }^{19,20}$ recent (i.e., in the previous 6 months) noninjection heroin use,$^{10}$ recent powder cocaine use (i.e., smoking and/or intranasal use), ${ }^{10}$ recent crack cocaine smoking, ${ }^{10,1920}$ recent cannabis use $^{19,20}$ and recent alcohol use..$^{20}$

First, we generated correlations between variables and tested for significant correlations using Pearson $\chi^{2}$ tests. We used Kaplan-Meier methods to calculate the cumulative hazard of injection in- itiation, stratified by crystal methamphetamine use. We then employed an a priori approach whereby basic sociodemographic variables (i.e., age, sex and ethnicity) were included in the final multivariable model, along with potential confounders significant at the $p<0.05$ level in univariable testing. This approach reflects recent guidance from Rothman and Greenland ${ }^{21}$ encouraging specification of minimal models compatible with available information. Finally, we undertook a subanalysis investigating the circumstances of first injection in an effort to identify specific microsetting phenomena accompanying injection initiation events. All statistical analyses were performed using SPSS software version 17.0 (SPSS, Chicago, IL).

\section{Results}

A total of 991 participants completed the At-Risk Youth Study baseline questionnaire between October 2005 and November 2010, of whom 395 (39.9\%) reported using crystal methamphetamine at baseline and 390 (39.4\%) reported injecting drugs at baseline. Those with a history of injection drug use at baseline were more likely to use crystal methamphetamine than those without a history of injection drug use (183/390 [46.9\%] v. 204/601 [33.9\%], $p<0.001)$. Among the 601 individuals who were injection-naive at baseline, 395 (65.7\%) had a follow-up visit to assess for injection initiation and were therefore eligible for inclusion in the present study. The 206 injection-naive participants who were ineligible for the present study because they had not yet returned for a follow-up

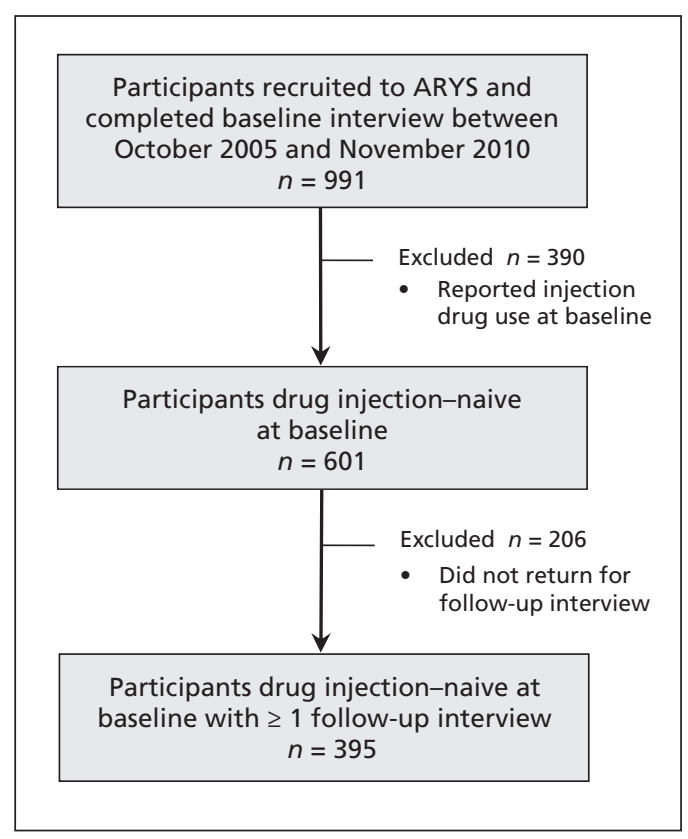

Figure 1: Flow diagram of recruitment and retention of participants in the At-Risk Youth Study (ARYS) and inclusion of participants in the current study. 
interview did not differ significantly from the study sample in terms of sex (142/206 [68.9\%] v. 269/395 [68.1\%] male), ethnicity (140/206 [68.0\%] v. 242/395 [61.3\%] white) or baseline crystal methamphetamine use $(67 / 206$ [32.5\%] v. $141 / 395$ [35.7\%]) (all $p>0.05$ ), although there was a 1-year difference in median age (20.7 v. 21.6, $p=0.002$ ). Figure 1 outlines the process of participant recruitment, retention and determination of eligibility for the present study.

In total, the 395 study participants provided 1434 observations over the study period. The median follow-up time was 21 (interquartile range [IQR] 13-26) months.

During the study period, 64 (16.2\%) of the participants reported initiating injection drug use, for a cumulative incidence of 21.7 (95\% confidence interval $[\mathrm{CI}] 1.7-41.7)$ per 100 person-years. The median age of first noninjection drug use was 14 (IQR 12-16) years among subsequent injection initiators and 12 (IQR 10-13) years among persistently injection-naive participants. Among the 141 participants who reported noninjection use of crystal methamphetamine at baseline, 137 (97.2\%) also reported cannabis use, 84 (59.6\%) reported noninjection crack cocaine use, 67 $(47.5 \%)$ reported noninjection powder cocaine use, and $32(22.7 \%)$ reported noninjection heroin use (Table 1).

Ethnicity was highly and significantly correlated with all other variables, including crystal methamphetamine use (Pearson $r=0.755, p<0.001$ ) (Table 2). After 36 months, the cumulative hazard of injection initiation was higher among participants who reported crystal methamphetamine use than among those who did not report use of this drug (32.3\% v. $13.3 \% ; p=0.010)$ (Figure 2).

In the multivariable analysis, recent noninjection crystal methamphetamine use (adjusted hazard ratio [HR] $1.93,95 \%$ CI 1.31-2.85) and recent noninjection heroin use (adjusted HR $1.73,95 \%$ CI 1.09-2.74) were associated with an increased risk of injection initiation (Table 3). By contrast, older age (adjusted HR 0.81, 95\% CI 0.75-0.88) and white ethnicity (adjusted HR $0.24,95 \%$ CI $0.11-0.49$ ) were negatively associated with the risk of injection initiation.

Among participants who responded to questions on the circumstances of their initiation events, 50\% (15/30) reported receiving their first injected drug as a gift. The drug of first injection was most commonly crystal methamphetamine (14/31 [45\%]), followed by heroin (9/31 [29\%]) and cocaine (3/31 [10\%]). Almost all respondents (16/17 [94\%]) reported that they did not believe that their use of drugs was out of control before the first injection. Furthermore, 19 (68\%) of 28 participants reported that they had not considered injecting before the initiation event.

Although the reported microsettings for injection initiation were diverse, 12 (39\%) of 31 participants reported initiating injection drug use in an outdoor public space. In terms of geographic setting, the largest proportion of participants reported initiating injection in Vancouver's Downtown Eastside neighbourhood (14/30 [47\%]), the site of a large open-air illicit drug market. Another 20\% (6/30) reported initiating injection in the Downtown South, an adjacent neighbourhood previously identified as a poten-

\begin{tabular}{|c|c|c|c|}
\hline \multirow[b]{2}{*}{ Characteristic } & \multicolumn{3}{|c|}{ Use of crystal methamphetamine; no. (\%) of participants* } \\
\hline & $\begin{array}{c}\text { Total } \\
n=395\end{array}$ & $\begin{array}{c}\text { No } \\
n=254\end{array}$ & $\begin{array}{c}\text { Yes } \\
n=141\end{array}$ \\
\hline \multicolumn{4}{|l|}{ Sociodemographic } \\
\hline Age, yr, median (IQR) & $21.6(19.6-23.3)$ & $21.7(19.5-23.6)$ & $21.4(19.7-22.8)$ \\
\hline Sex, male & $269(68.1)$ & $177(69.7)$ & $92(65.2)$ \\
\hline Ethnicity, white & $242(61.3)$ & $147(57.9)$ & $95(67.4)$ \\
\hline \multicolumn{4}{|l|}{ Recent drug uset } \\
\hline Cocaine & $194(49.1)$ & $127(50.0)$ & $67(47.5)$ \\
\hline Crack cocaine & $221(55.9)$ & $137(53.9)$ & $84(59.6)$ \\
\hline Heroin & $63(15.9)$ & $31(12.2)$ & $32(22.7)$ \\
\hline Cannabis & 389 (98.5) & $252(99.2)$ & $137(97.2)$ \\
\hline Alcohol & $69(17.5)$ & $50(19.7)$ & 19 (13.5) \\
\hline
\end{tabular}


tial geographic area of transition into drug dependence among street-involved youth. ${ }^{22-24}$ Participants reported that a variety of individuals were present at initiation events, including friends (17/30 [57\%]), family members (4/30 [13\%]) and acquaintances $(3 / 30[10 \%])$. However, $17 \%$ of respondents $(5 / 30)$ reported initiating injection drug use alone. All but one of the initiates (30/31 [97\%]) reported that they had not shared needles during their first injection experiences. A majority of participants $(25 / 31$ [81\%]) reported that someone else performed the injection during the initiation event. Finally, fewer than half of participants (12/29 [41\%]) reported subsequently becoming regular injection drug users during the study period.

\section{Interpretation}

Within a sample of street-involved youth in a Canadian setting, recent noninjection use of crystal methamphetamine was independently associated with an increased risk of subsequent initiation of injection drug use. Furthermore, within a subsample of first-time injection drug users, crystal methamphetamine was most commonly reported as the drug used during initiation events. Most studies of injection initiation have employed crosssectional or retrospective data. ${ }^{11,20,25-27}$ The retention rate of the current longitudinal study $(65.7 \%)$ was comparable to that of other longitudinal studies of injection initiation $\left(64 \%,{ }^{28} 67 \%{ }^{29}\right)$ but somewhat lower than that reported in another Canadian study

Table 2: Correlations between independent variables of interest

\begin{tabular}{|c|c|c|c|c|c|c|c|c|c|}
\hline \multirow[b]{2}{*}{ Variable } & \multirow[b]{2}{*}{$\begin{array}{l}\text { Ethnicity, } \\
\text { white }\end{array}$} & \multirow[b]{2}{*}{$\begin{array}{l}\text { Sex, } \\
\text { male }\end{array}$} & \multirow[b]{2}{*}{ Age, yr } & \multicolumn{6}{|c|}{ Recent drug use } \\
\hline & & & & Cocaine & Crack & Heroin & $\begin{array}{c}\text { Crystal } \\
\text { methamphetamine }\end{array}$ & Cannabis & Alcohol \\
\hline \multicolumn{10}{|l|}{ Ethnicity, white } \\
\hline Pearson correlation & 1 & 0.004 & -0.185 & 0.717 & 0.676 & 0.838 & 0.755 & 0.804 & 0.790 \\
\hline$p$ value (2-tailed) & NA & 0.888 & $<0.001$ & $<0.001$ & $<0.001$ & $<0.001$ & $<0.001$ & $<0.001$ & $<0.001$ \\
\hline \multicolumn{10}{|l|}{ Sex, male } \\
\hline Pearson correlation & & 1 & 0.218 & 0.017 & 0.029 & -0.018 & -0.015 & 0.121 & 0.011 \\
\hline$p$ value (2-tailed) & & NA & $<0.001$ & 0.559 & 0.310 & 0.532 & 0.606 & $<0.001$ & 0.714 \\
\hline \multicolumn{10}{|l|}{ Age, yr } \\
\hline Pearson correlation & & & 1 & -0.198 & 0.056 & -0.110 & -0.093 & -0.152 & -0.158 \\
\hline$p$ value (2-tailed) & & & NA & $<0.001$ & 0.052 & $<0.001$ & 0.001 & $<0.001$ & $<0.001$ \\
\hline \multicolumn{10}{|l|}{ Recent drug use* } \\
\hline \multicolumn{10}{|l|}{ Cocaine } \\
\hline Pearson correlation & & & & 1 & 0.528 & 0.627 & 0.555 & 0.639 & 0.644 \\
\hline$p$ value (2-tailed) & & & & NA & $<0.001$ & $<0.001$ & $<0.001$ & $<0.001$ & $<0.001$ \\
\hline \multicolumn{10}{|l|}{ Crack } \\
\hline Pearson correlation & & & & & 1 & $0.666 \dagger$ & 0.546 & 0.589 & 0.556 \\
\hline$p$ value (2-tailed) & & & & & NA & $<0.001$ & $<0.001$ & $<0.001$ & $<0.001$ \\
\hline \multicolumn{10}{|l|}{ Heroin } \\
\hline Pearson correlation & & & & & & 1 & 0.689 & 0.666 & 0.661 \\
\hline$p$ value (2-tailed) & & & & & & NA & $<0.001$ & $<0.001$ & $<0.001$ \\
\hline \multicolumn{10}{|c|}{ Crystal methamphetamine } \\
\hline Pearson correlation & & & & & & & 1 & 0.642 & 0.572 \\
\hline$p$ value (2-tailed) & & & & & & & NA & $<0.001$ & $<0.001$ \\
\hline \multicolumn{10}{|l|}{ Cannabis } \\
\hline Pearson correlation & & & & & & & & 1 & 0.658 \\
\hline$p$ value (2-tailed) & & & & & & & & NA & $<0.001$ \\
\hline \multicolumn{10}{|l|}{ Alcohol } \\
\hline Pearson correlation & & & & & & & & & 1 \\
\hline$p$ value (2-tailed) & & & & & & & & & NA \\
\hline
\end{tabular}


of injection initiation (in Montréal), which had a follow-up rate of $89 \% .^{10}$

Canadian surveillance data suggest that reported levels of crystal methamphetamine use in the previous 3 months among street-involved youth aged 15-24 years increased significantly in the early $2000 \mathrm{~s}$, from $2.5 \%$ in 1999 to $9.5 \%$ in $2005 .{ }^{30}$ This trend is consistent with global patterns of crystal methamphetamine use, according to data from the United Nations Office on Drugs and Crime. ${ }^{13}$ Indeed, methamphetamine remains widely available, and levels of methamphetamine use remain high among youth, particularly in Southeast Asia and North America. ${ }^{13}$ This likely reflects the relative ease with which amphetamine-type stimulants can be produced, as well as the fact that, unlike available opioidsubstitution treatments, few effective stimulantsubstitution treatment options exist. ${ }^{31}$ Furthermore, a recent review of clinical treatment for methamphetamine dependence noted the dearth of effective treatment options for this drug, stating that one barrier to the development of treatment has been inadequate research on the characteristics and consequences of use of this drug. ${ }^{31}$

The data presented here appear highly relevant in the context of these upward trends. Specifically, whereas previous research has identified a variety of serious health harms associated with crystal methamphetamine use, ${ }^{32}$ the current study has identified use of this drug as a risk factor for injection initiation. Although the data were incomplete, we found in the present study that not only was noninjection use of crystal methamphetamine associated with subsequent injection drug use, but also that crystal methamphetamine was most commonly reported as the drug of first injection. These results differ from a study of street youth in Montréal, in which use of cocaine (both powder and crack cocaine) was significantly associated with subsequent injection initiation. However, rates of methamphetamine use were much lower in that setting. Notably, although both crack cocaine and methamphetamine are commonly used and widely available ${ }^{14}$ the independent effect of methamphetamine on increasing the risk of injection initiation in the current study nevertheless remained.

With respect to specific drug-related risks for initiation, both the Risk Evaluation and Assessment of Community Health (REACH) III study ${ }^{20}$ and the Montréal Street Youth Cohort study ${ }^{10}$ concluded that individuals identified as being at high risk of initiating injection drug use require more peer-delivered information regarding different routes of drug administration (e.g., injection v. noninjection) and their consequences. To that end, some studies have suggested that older injection drug users should be enlisted in efforts to educate younger drug users regarding the harms of transitioning to injection drug use. ${ }^{33}$ Our current findings regarding the microsetting characteristics of injection initiation events elucidate the context-

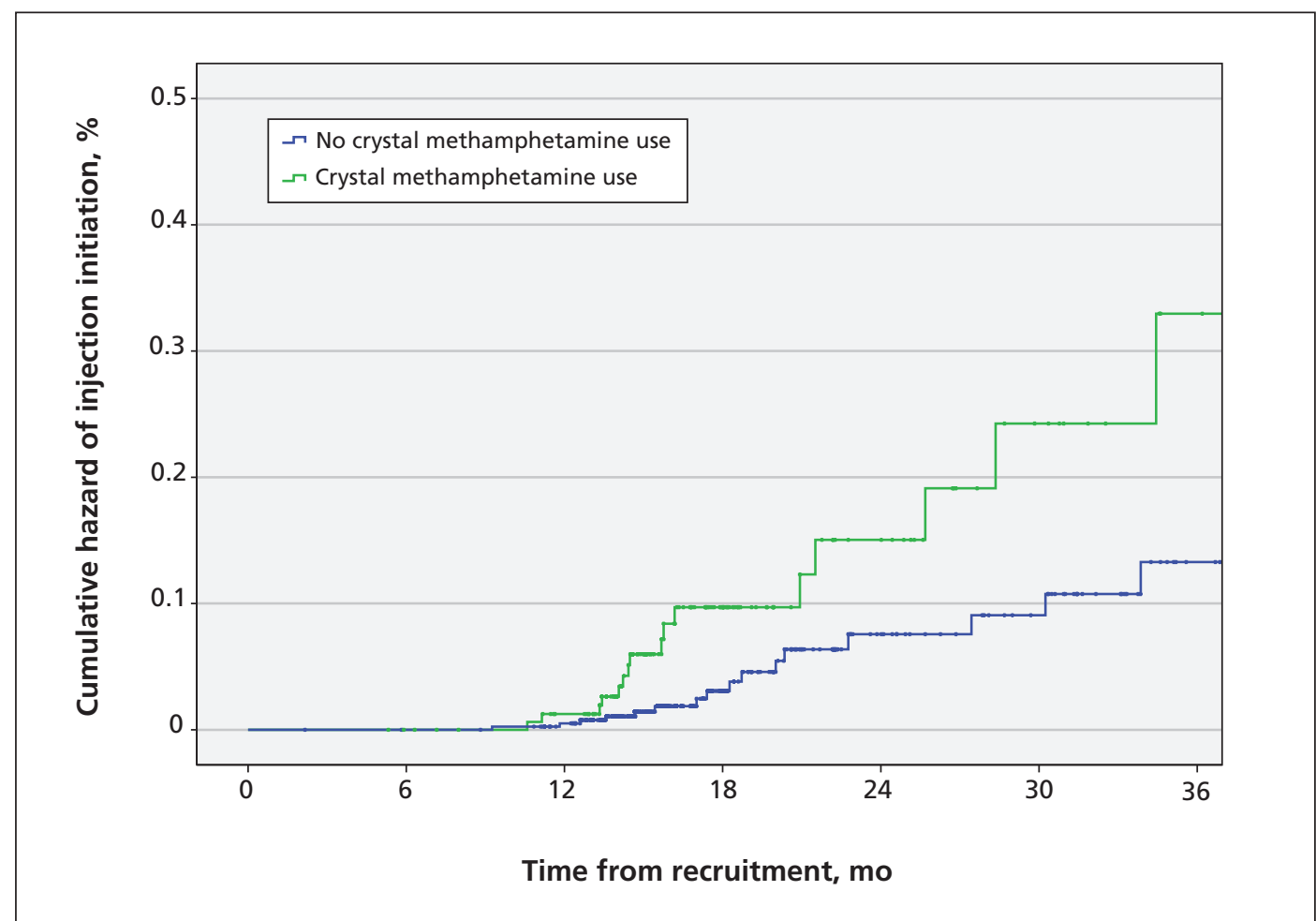

Figure 2: Cumulative hazard of injection initiation among street-involved youth, stratified by use of crystal methamphetamine in Vancouver, British Columbia, October 2005 to November $2010(n=395)$. 
specific roles that other injection drug users may play in determining risk of injection initiation among street-involved youth. Specifically, half of the subsample of injection initiates reported receiving the injected drug as a gift, and over fourfifths reported that someone else had performed the injection during their initiation event. These findings suggest that drug-using peers and established injection drug users may play a critical role in initiating street-based young people into injection drug use through a variety of roles. However, one potential avenue to mitigate the impact of established injection drug users may be increasing community access to evidence-based forms of addiction treatment. Given that this approach has the potential to reduce the overall number of injection drug users in a community, it may therefore help in reducing youth exposure to established injection drug users in general.

\section{Limitations}

This study had limitations consistent with observational studies of drug-using populations. First, although the At-Risk Youth Study reflects many characteristics representative of street-involved youth living in Vancouver, ${ }^{3,35}$ the lack of registries of such young people meant that recruitment was not randomized. The generalizability of this study may therefore be limited, particularly as few, if any, previous studies have been able to investigate the potential role of crystal methamphetamine use in increasing the risk of injection initiation among street-involved youth. Second, the potential exists that those injection-naive participants who were

Table 3: Unadjusted and adjusted hazard ratios for factors related to initiation of injection drug use among street-involved youth in Vancouver, British Columbia, 2005-2010 $(n=395)$

\begin{tabular}{|lcc|}
\hline & \multicolumn{2}{c|}{ Hazard ratio $(95 \% \mathrm{Cl})$} \\
\cline { 2 - 3 } Characteristic & Unadjusted & Adjusted \\
\hline Sociodemographic & & \\
\hline Age (per yr older) & $0.91(0.86-0.97)$ & $0.81(0.75-0.88)$ \\
\hline Male sex & $0.61(0.42-0.88)$ & $0.90(0.60-1.36)$ \\
\hline White ethnicity (v. other) & $1.28(0.87-1.89)$ & $0.24(0.11-0.49)$ \\
\hline Recent drug use* & & - \\
\hline Cocaine & $0.94(0.73-1.21)$ & - \\
\hline Crack & $1.20(0.93-1.56)$ & $1.73(1.09-2.74)$ \\
\hline Heroin & $1.39(1.06-1.82)$ & $1.93(1.31-2.85)$ \\
\hline $\begin{array}{l}\text { Crystal } \\
\text { methamphetamine }\end{array}$ & $1.51(1.19-1.99)$ & - \\
\hline Cannabis & $0.94(0.67-1.26)$ & - \\
\hline Alcohol & $1.02(0.77-1.37)$ & - \\
\hline
\end{tabular}

Note: $\mathrm{Cl}=$ confidence interval.

*All drug-use variables refer to noninjection use in the preceding 6 months. lost to follow-up may have differed from the study participants on other unmeasured factors that could have affected the study findings. In this regard, it is noteworthy that those lost to follow-up did not differ significantly in terms of crystal methamphetamine use or key sociodemographic factors other than age. Third, illicit drug use remains highly stigmatized, which may have affected participants' responses ${ }^{36}$ although such bias might not have affected the response patterns of initiators and noninitiators differently. Fourth, we cannot rule out the potential for confounding as a result of exposures or participant traits that were not measured as part of the present study. For instance, illicit stimulant use has been associated with psychiatric disorders, including attention-deficit/hyperactivity disorder. ${ }^{37,38}$ Unfortunately, standardized assessment of psychiatric disorders was not undertaken as part of the At-Risk Youth Study. Similarly, there is increasing recognition of genetic factors that may predispose individuals to addictive disorders and high-risk drug use, ${ }^{39}$ and these data were also not available in the present study. Nevertheless, we identified a strong independent association between crystal methamphetamine use and subsequent injection drug use, a finding with immediate policy implications. Finally, data on the circumstances of injection were not available for all incident cases of injection initiation. Further research, including qualitative methods, may be useful in more fully elucidating the lived experience of drug-use activities and the social circumstances that contribute to initiation of injection drug use in high-risk populations.

\section{Conclusion}

In this study of drug-related risks for injection initiation among street-involved youth, noninjection use of crystal methamphetamine was independently associated with an increased risk of injection initiation, after adjustment for sociodemographic and drug-related confounders. In a subanalysis of the circumstances of first injection, the largest proportion of participants reported initiating injection with crystal methamphetamine. Addressing the impact of crystal methamphetamine use in increasing the risk of injection initiation among injection-naive streetinvolved youth represents an urgent public health priority. ${ }^{9,4}$ Development and evaluation of appropriate interventions are therefore critically needed. Indeed, consistent with calls for an increased focus on the prevention of injection drug use,,${ }^{9,40}$ further research is required to develop and test evidence-based interventions to prevent injection drug use in ways that accommodate the complexities of crystal methamphetamine and polydrug use. 


\section{References}

1. Fuller CM, Vlahov D, Ompad DC, et al. High-risk behaviors associated with transition from illicit non-injection to injection drug use among adolescent and young adult drug users: a casecontrol study. Drug Alcohol Depend 2002;66:189-98.

2. AIDS epidemic update: November 2009. Geneva (Switzerland): Joint United Nations Programme on HIV/AIDS; 2009.

3. Backmund M, Reimer J, Meyer K, et al. Hepatitis C virus infection and injection drug users: prevention, risk factors, and treatment. Clin Infect Dis 2005;40:S330-5.

4. Darke S, Hall W. Heroin overdose: research and evidence-based intervention. J Urban Health 2003;80:189-200.

5. Brugal MT, Barrio G, Fuente LDL, et al. Factors associated with non-fatal heroin overdose: assessing the effect of frequency and route of heroin administration. Addiction 2002;97:319-27.

6. Garfein RS, Vlahov D, Galai N, et al. Viral infections in shortterm injection drug users: the prevalence of the hepatitis $\mathrm{C}$ hepatitis B, human immunodeficiency, and human Tlymphotropic viruses. Am J Public Health 1996;86:655-61.

7. Tagliaro F, Battisti ZD, Smith FP, et al. Death from heroin overdose: findings from hair analysis. Lancet 1998;351:1923-5.

8. van Haastrecht HJA, Van Ameijden EJC, Van Den Hoek JAR, et al. Predictors of mortality in the Amsterdam cohort of human immunodeficiency virus (HIV)-positive and HIV-negative drug users. Am J Epidemiol 1996;143:380-91.

9. Vlahov D, Fuller CM, Ompad DC, et al. Updating the infection risk reduction hierarchy: preventing transition into injection. $J$ Urban Health 2004;81:14-9.

10. Roy E, Haley N, Leclerc P, et al. Drug injection among street youths in Montréal: predictors of initiation. J Urban Health 2003;80:92-105.

11. Fuller CM, Vlahov D, Arria AM, et al. Factors associated with adolescent initiation of injection drug use. Public Health Rep 2001;116(Suppl 1):136-45.

12. Wood E, Stolz JA, Montaner JS, et al. Evaluating methamphetamine use and risks of injection initiation among street youth: the ARYS study. Harm Reduct $J$ 2006;3:1.

13. World drug report 2012. Vienna (Austria): United Nations Office on Drugs and Crime; 2012.

14. Drug situation in Vancouver. Vancouver (BC): BC Centre for Excellence in HIV/AIDS, Urban Health Research Initiative; 2013.

15. Colfax G, Santos GM, Chu P, et al. Amphetamine-group substances and HIV. Lancet 2010;376:458-74.

16. Boivin JF, Roy E, Haley N, et al. The health of street youth. Can $J$ Public Health 2005;96:432-7.

17. DeMatteo D, Major C, Block B, et al. Toronto street youth and HIV/AIDS: prevalence, demographics, and risks. J Adolesc Health 1999;25:358-66.

18. Elliott AS. Meeting the health care needs of street-involved youth. Paediatr Child Health 2013;18:317-21.

19. Fuller CM, Borrell LN, Latkin CA, et al. Effects of race, neighborhood, and social network on age at initiation of injection drug use. Am J Public Health 2005;95:689-95.

20. Sherman SG, Fuller CM, Shah N, et al. Correlates of initiation of injection drug use among young drug users in Baltimore, Maryland: the need for early intervention. J Psychoactive Drugs 2005;37:437-43.

21. Rothman K, Greenland S. Modern epidemiology. 3rd ed Philadelphia (PA): Lippincott Williams \& Wilkins; 2008.

22. Fast D, Small W, Wood E, et al. Coming 'down here': young people's reflections on becoming entrenched in a local drug scene. Soc Sci Med 2009;69:1204-10.

23. Werb D, Kerr T, Fast D, et al. Drug-related risks among street youth in two neighborhoods in a Canadian setting. Health Place 2010;16:1061-7.

24. Fast D, Shoveller J, Shannon K, et al. Safety and danger in downtown Vancouver: understandings of place among young people entrenched in an urban drug scene. Health Place 2010;16:51-60.

25. Trenz RC, Harrell P, Scherer M, et al. A model of school problems, academic failure, alcohol initiation, and the relationship to adult heroin injection. Subst Use Misuse 2012;47:1159-71.

26. Crofts N, Louie R, Rosenthal D, et al. The first hit: circumstances surrounding initiation into injecting. Addiction 1996;91:1187-96.

27. Young AM, Havens JR. Transition from first illicit drug use to first injection drug use among rural Appalachian drug users: a cross-sectional comparison and retrospective survival analysis. Addiction 2012;107:587-96.

28. Neaigus A, Gyarmathy VA, Miller M, et al. Transitions to injecting drug use among noninjecting heroin users: social network influence and individual susceptibility. J Acquir Immune Defic Syndr (1999) 2006;41:493-503.

29. Buster MCA, Witteveen E, Prins M, et al. Transitions in drug use in a new generation of problem drug users in Amsterdam: a 6-year follow-up study. Eur Addict Res 2009;15:179-87.

30. Epi-update: crystal methamphetamine use among Canadian street-involved youth (1999-2005). Ottawa (ON): Public Health Agency of Canada; 2009

31. Cretzmeyer M, Sarrazin MV, Huber DL, et al. Treatment of methamphetamine abuse: research findings and clinical directions. J Subst Abuse Treat 2003;24:267-77.

32. Marshall BDL, Werb D. Health outcomes associated with methamphetamine use among young people: a systematic review. Addiction 2010;105:991-1002.

33. Ouellet LJ, Bailey SL. Drug injection initiation and hepatitis C virus (HCV) infection: an assessment of opportunities for intervention [abstract]. National Viral Hepatitis Prevention Conference; 2005 Dec. 5-9; Washington (DC).

34. Against the odds: a profile of marginalized and street-involved youth in BC. Vancouver (BC): The McCreary Centre Society; 2007.

35. Street youth in Canada. Ottawa (ON): Public Health Agency of Canada; 2006.

36. Macalino GE, Celentano DD, Latkin C, et al. Risk behaviors by audio computer-assisted self-interviews among HIV-seropositive and HIV-seronegative injection drug users. AIDS Educ Prev $2002 ; 14: 367-78$

37. Gudjonsson GH, Sigurdsson JF, Sigfusdottir ID, et al. An epidemiological study of ADHD symptoms among young persons and the relationship with cigarette smoking, alcohol consumption and illicit drug use. J Child Psychol Psychiatry 2012;53:304-12.

38. Szobot CM, Rohde LA, Bukstein O, et al. Is attentiondeficit/hyperactivity disorder associated with illicit substance use disorders in male adolescents? A community-based casecontrol study. Addiction 2007;102:1122-30.

39. Volkow ND, Li TK. Drug addiction: the neurobiology of behaviour gone awry. Nat Rev Neurosci 2004;5:963-70.

40. Beyrer C, Malinowska-Sempruch K, Kamarulzaman A, et al. Time to act: a call for comprehensive responses to HIV in people who use drugs. Lancet 2010;376:551-63.

Affiliations: BC Centre for Excellence in HIV/AIDS (Werb, Kerr, Montaner, Wood); School of Population and Public Health (Werb, Buxton, Shoveller, Richardson) and Division of AIDS (Kerr, Montaner, Wood), University of British Columbia; British Columbia Centre for Disease Control (Buxton), Vancouver, BC.

Contributors: All authors had full access to all of the data and have read and approved the text as submitted to CMAJ. Dan Werb and Evan Wood performed the initial analyses and drafted the manuscript. Thomas Kerr, Jane Buxton, Jeannie Shoveller, Chris Richardson and Julio Montaner all contributed to data collection and analysis and to manuscript revisions.

Funding: The study was supported by the US National Institutes of Health (R01DA028532) and the Canadian Institutes of Health Research (MOP-102742). Dan Werb is supported by the Canadian Institutes of Health Research and the Trudeau Foundation. Thomas Kerr is supported by the Michael Smith Foundation for Health Research. Jeannie Shoveller is supported by the Canadian Institutes of Health Research and the Michael Smith Foundation for Health Research. This research was undertaken, in part, thanks to funding from the Canada Research Chairs program through a Tier 1 Canada Research Chair in Inner City Medicine supporting Evan Wood. The funders had no role in the design and conduct of the study; the collection, management, analysis and interpretation of the data; the preparation, review or approval of the manuscript; or the decision to submit the manuscript for peer review.

Acknowledgements: The authors thank the study participants for their contribution to the research, as well as current and past researchers and staff. The authors specifically thank Deborah Graham, Peter Vann, Caitlin Johnston and Steve Kain for their research and administrative assistance. 